\title{
Temperaturas e períodos de molhamento foliar no desenvolvimento da ferrugem alaranjada da cana-de-açúcar (Puccinia kuehnii)
}

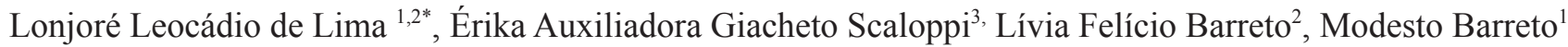

\begin{abstract}
${ }^{1}$ Departamento de Fitossanidade, Faculdade de Ciências Agrárias e Veterinárias/ Universidade Estadual Paulista, Via de Acesso: Prof. Paulo Donato Castellane s/n, 14.884-900, Jaboticabal, SP, Brasil; ${ }^{2}$ Aluna de Pós - graduação - UNESP/FCAV, ${ }^{3}$ APTA. Centro Leste, Av. Bandeirantes, 2419, 14030-670, Ribeirão Preto-SP. *Parte da tese de doutorado do primeiro autor.
\end{abstract}

Autor para correspondência: Lonjoré Leocádio de Lima (lonjore@hotmail.com)

Data de chegada: 25/04/2013. Aceito para publicação em: 13/11/2014.

$10.1590 / 0100-5405 / 1890$

\section{RESUMO}

Lima, L.L.; Scaloppi, E.A.G.; Barreto, L.F.; Barreto, M.. Temperaturas e períodos de molhamento foliar no desenvolvimento da ferrugem alaranjada da cana-de-açúcar (Puccinia kuehnii). Summa Phytopathologica, v.43, n.2, p.132-135, 2017.

Devido à escassez de estudos epidemiológicos da ferrugem alaranjada da cana-de-açúcar no Brasil e a importância dessa cultura no agronegócio brasileiro, objetivou-se neste trabalho determinar a influência da temperatura e do período de molhamento foliar na epidemiologia dessa doença. Foram utilizadas plantas da cultivar SP89-1115 com vinte dias de idade inoculadas com o fungo Puccinia kuehnii na concentração de $2 \times 10^{4}$ de uredósporos $/ \mathrm{mL}$. $\mathrm{O}$ delineamento experimental utilizado foi inteiramente casualizado (DIC) em esquema fatorial $5 \times 7$ sendo cinco temperaturas $(17,5 ; 20,0 ; 22,5 ; 25,0$ e $\left.27,5^{\circ} \mathrm{C}\right)$ e sete períodos de molhamento foliar $(0 ; 4 ; 8 ; 12 ; 16 ; 20$ e 24 horas $)$, com três repetições. As melhores temperaturas para o desenvolvimento da ferrugem alaranjada foram 20,$0 ; 22,5$ e $25,0^{\circ} \mathrm{C}$ sendo esta última a melhor. Nas temperaturas de 22,5 e $25,0^{\circ} \mathrm{C}$ com 20 horas de molhamento foliar foram observadas que as pústulas apresentaram-se em maior número decrescendo com 24 horas de molhamento. Não foi observado sintomas da doença nos períodos de molhamentos foliares de $0,4 \mathrm{e} 8$ horas em todas as temperaturas testadas. Também não ocorreu a doença na temperatura de $27,5^{\circ} \mathrm{C}$ em todas as combinações dos períodos de molhamentos foliares testados. Estudos de epidemiologia dessa doença são importantes para traçar estratégias de controle e futuramente desenvolver um sistema de previsão para a ferrugem alaranjada da cana-de-açúcar.

Palavras-chave: Epidemiologia, Saccharum spp, Fatores climáticos.

\section{ABSTRACT}

Lima, L.L.; Scaloppi, E.A.G.; Barreto, L.F.; Barreto, M.. Temperatures and leaf wetness duration on orange rust development in sugarcane ( Puccinia kuehnii). Summa Phytopathologica, v.43, n.2, p.132-135, 2017.

Considering the lack of epidemiological studies on orange rust of sugarcane in Brazil and the importance of this crop in the Brazilian agribusiness, the aims of this study were to determine the influence of temperature and leaf wetness duration on the epidemiology of this disease. Twenty-day-old plants of the cultivar SP 89-1115 were inoculated with the fungus Puccinia kuehnii at a concentration of $2 \times 10^{4}$ urediniospores.mL. Experimental design was completely randomized (DIC), in 5x7 factorial arrangement, representing five temperatures $\left(17.5,20.0,22.5,25.0\right.$ and $\left.27.5^{\circ} \mathrm{C}\right)$ and seven leaf wetness periods $(0,4,8,12,16,20$ and 24 hours), including three replicates. Ideal temperatures for orange rust development were $20.0,22.5$ and $25.0^{\circ} \mathrm{C}$, of which the latter was the best. At temperatures of 22.5 and $25.0^{\circ} \mathrm{C}$, pustules increased in number with 20 hours leaf wetness but decreased with 24 hours wetness. No disease symptoms were observed at 0,4 and 8 hours leaf wetness for all tested temperatures. Similarly, the disease did not occur at a temperature of $27.5^{\circ} \mathrm{C}$ for all tested combinations of leaf wetness duration. Epidemiological studies of this disease are important to devise control strategies and eventually develop a forecasting system for orange rust of sugarcane.

Keywords: Epidemiology, Saccharum spp., weather factors

De acordo com a Companhia Nacional de Abastecimento - Conab (7) a produção de cana-de-açúcar no Brasil na safra 2015/2016 foi de aproximada 665 milhões toneladas e a previsão para 2016/2017 e que chegue a 694,5 milhões toneladas.

Vários fatores são limitantes à produção da cana-de-açúcar dentre eles a ocorrência de doenças, levando a substituição de variedades, devido ao decréscimo que as mesmas promovem na produtividade. Uma das principais doenças fúngicas da cana-de-açúcar é a ferrugem alaranjada causada pelo fungo Puccinia kuehnii (Krüger) Butler. Embora de ocorrência recente, no Brasil e em vários outros países foram observadas danos superiores a $40 \%$ para variedades suscetíveis e intermediárias (4).

A ferrugem alaranjada é uma doença antiga na Ásia e Oceania e até o ano 2000 não havia relatos de danos à produção da cana-deaçúcar. Porém nesse referido ano os danos foram superiores a $40 \%$ na Austrália (12) e o fungo disseminando rapidamente para vários países. No Brasil, a doença foi detectada pela primeira vez em 2009, nas proximidades do município de Rincão na região de Araraquara no estado de São Paulo (5).

Os sintomas iniciais caracterizam-se por manchas cloróticas nas 
folhas mais jovens, observadas comumente na face inferior da folha. As lesões evoluem rapidamente e coalescem em variedades altamente suscetíveis, causando a necrose das folhas. As urédias formam uma minúscula protuberância de coloração laranja a castanho avermelhado (8).

As condições ambientais favoráveis para o desenvolvimento da ferrugem alaranjada são umidade relativa alta, temperaturas elevadas no verão $(13,16)$ com alternância de calor e frio no outono (13). Sendo as condições ótimas de germinação, de acordo com Magarey et al. (14): temperaturas entre 22 e $24^{\circ} \mathrm{C}$ e umidade relativa entre 98 e $99 \%$.

Quando se considera todo o ciclo de uma doença os fatores ambientais, tais como temperatura, umidade relativa, orvalho, luminosidade, vento, radiação solar e chuva, podem afetar os processos de infecção, colonização, reprodução, disseminação e sobrevivência do patógeno (9). Portanto a determinação dessas variáveis torna-se, fundamental para a identificação do potencial de risco de ocorrência de doenças nas culturas e na tomada de decisão quanto à realização do controle (11).

Devido à escassez de estudos quanto aos aspectos epidemiológicos da ferrugem alaranjada da cana-de-açúcar no Brasil e à importância dessa cultura no agronegócio brasileiro, objetivou-se neste trabalho determinar a influência da temperatura e do período de molhamento foliar na epidemiologia da ferrugem alaranjada da cana-de-açúcar.

\section{MATERIAL E MÉTODOS}

Esse trabalho foi realizado no Laboratório de Fitopatologia, do Departamento de Fitossanidade da UNESP/FCAV (Câmpus de Jaboticabal) e a metodologia utilizada foi adaptada de Martins (15).

O inóculo foi obtido de folhas de cana-de-açúcar da cultivar SP891115 infectada com P. kuehnii. Para isso as folhas foram colocadas em câmara úmida por 24 horas para obtenção da esporulação. Posteriormente foi realizada a transferência das estruturas do fungo com auxílio de um pincel de cerdas macias, para um béquer contendo água destilada, e em seguida a concentração do inóculo foi ajustada para aproximadamente $2 \times 10^{4}$ uredósporos $/ \mathrm{mL}$.

A suspensão do inóculo ajustada foi pulverizada até o ponto de escorrimento, sobre ambas as superfícies das folhas, em plantas com 20 dias de idade da cultivar SP89-1115, suscetível. Foi utilizado um pulverizador manual de $0,5 \mathrm{~L}$ de capacidade. As plantas inoculadas foram produzidas a partir de colmos cortados em mini-toletes apenas com uma gema para que coubessem em copos plásticos de $200 \mathrm{~mL}$ de volume, preenchidos com uma mistura de três partes de solo (Latossolo - roxo), uma de areia lavada e uma de esterco bovino curtido e acrescido de fertilizante. A irrigação foi realizada, com auxílio de uma piceta, sempre que necessária.

O delineamento experimental utilizado foi inteiramente casualizado (DIC) em esquema fatorial $5 \times 7$ sendo cinco temperaturas $(17,5 ; 20,0$; 22,$5 ; 25,0$ e $\left.27,5^{\circ} \mathrm{C}\right)$ e sete períodos de molhamento foliar $(0 ; 4 ; 8 ; 12$; 16; 20 e 24 horas), com 3 repetições.

Foi avaliado o período de molhamento foliar e a temperatura para o desenvolvimento da doença. Para tanto, imediatamente após a inoculação, as plantas foram cobertas com sacos plásticos transparentes umedecidos e mantidas em estufa incubadora tipo B.O.D. com fotoperíodo de $12 \mathrm{~h} / 12 \mathrm{~h}$ por diferentes períodos de molhamento e temperaturas que constituíram nos tratamentos do ensaio. O molhamento zero correspondeu à ausência de câmara úmida. A variação da temperatura das estufas incubadora tipo B.O.D. foi de aproximadamente $\pm 2{ }^{\circ} \mathrm{C}$.
Todas as plantas foram avaliadas diariamente após a inoculação até o início dos primeiros sintomas avaliou-se a severidade das folhas (porcentagem de área foliar doente) utilizando uma escala descritiva de notas de Amorim et al. (3) para ferrugem marrom (Puccinia melanocephala Syd. \& P. Syd.) adaptada para a ferrugem alaranjada onde: Nota $\mathbf{1}=$ Ausência de doença, $\mathbf{2}=0,5 \%, \mathbf{3}=0,6$ até $1 \%, \mathbf{4}=1,1$ até $5 \%, \mathbf{5}=5,1$ até $10 \%, \mathbf{6}=10,1$ até $25 \%, \mathbf{7}=25,1$ até $35 \%, \mathbf{8}=35,1$ até $50 \%$ e $9=>50 \%$ de área foliar lesionada.

Apesar das avaliações terem sido realizadas diariamente, para fins de análise estatística, foram utilizadas as notas em intervalo de dois dias até a última avaliação, totalizando cinco avaliações. As notas foram convertidas para porcentagens de área foliar doente pelo ponto médio de cada nota. Os dados de severidade da doença foi integralizada como área abaixo da curva de progresso da doença (AACPD), através da equação citada por Shaner \& Finney (17) :

$$
\mathrm{AACPD}=\sum_{i=1}^{n-1}\left[\frac{Y_{i}+Y_{i+1}}{2}\right]\left(t_{i+1}+t_{i}\right)
$$

AACPD = área abaixo da curva de progresso da doença $\mathrm{n}=$ número de observações

$\mathrm{Y}_{\mathrm{i}}=$ severidade da doença na i-ésima observação

$\mathrm{T}_{\mathrm{i}}=$ tempo em dias na i-ésima observação

$\mathrm{n}=$ número total de observações

Com os dados das avaliações da doença foi possível o ajuste do modelo de regressão não linear, pela função beta-monomolecular Hau $\&$ Kranz, (10) expressa pela equação $Z=\left\{b 1 \times\left[(T-b 2)^{\mathrm{b} 3}\right] \times\left[(\mathrm{b} 4-\mathrm{T})^{\mathrm{b} 5}\right]\right.$ $\mathrm{x}[\mathrm{b} 6 \mathrm{x}[(1-\mathrm{b} 7 \mathrm{x} \exp (-\mathrm{b} 8 \mathrm{x} \mathrm{M})]\}$ onde T corresponde a temperatura; $\mathrm{M}$ o período de molhamento foliar; b2 e b4 são as temperaturas mínima e máximas respectivamente ; b5 representa a amplitude da curva em sua faixa assintótica; b8 está relacionada à velocidade de aumento da variável dependente em função do molhamento e os demais são parâmetros desprovidos de significados biológicos.

O modelo beta-monomolecular foi ajustado com auxílio do software Statistica ${ }^{\circledR}$. Os dados da severidade máxima foram analisados pelo teste $\mathrm{F}$ para variância e os dados foram transformados em $\sqrt{x+1} \mathrm{e}$ comparados pelo teste de Tukey a $5 \%$ de probabilidade.

\section{RESULTADOS E DISCUSSÃO}

Nas plantas inoculadas e mantidas em cinco diferentes temperaturas e sete períodos de molhamento foliar, os primeiros sintomas da ferrugem foram observados aos 10 dias após a inoculação na temperatura de $25^{\circ} \mathrm{C}$, a partir do molhamento foliar de 12 horas. Nesta temperatura as pústulas apresentaram-se pequenas e com severidade reduzida em torno de $5 \%$. Já nas temperaturas de 20,0 e $22,5^{\circ} \mathrm{C}$ os primeiros sintomas da doença foram observados aos 12 dias, nos molhamentos foliares de 16 e 20 horas. Nos molhamentos foliares 12 e 24 horas, aos 12 dias, as folhas apresentaram áreas despigmentadas que posteriormente verificou-se evoluir para sintomas da ferrugem.

Na temperatura de $17,5^{\circ} \mathrm{C}$ os sintomas foram observados, somente aos 14 dias após a inoculação, apenas nos molhamentos de 20 e 24 horas e de forma menos agressiva com apenas $0,3 \%$ de severidade. Não foi observado sintoma da doença nos períodos de molhamentos foliares de 0,4 e 8 horas em todas as temperaturas testadas. Também não ocorreu a doença na temperatura de $27,5^{\circ} \mathrm{C}$ em todas as combinações dos períodos de molhamentos foliares testados (Tabela 1). 
Tabela 1. Médias da severidade da ferrugem alaranjada da cana-deaçúcar (Puccinia kuehnii) em plantas da cultivar SP89-1115 inoculadas, em diferentes combinações de temperatura e molhamento foliar.

\begin{tabular}{|c|c|}
\hline Temperatura & Severidade \\
\hline 17,5 & $0,08 \mathrm{c}$ \\
\hline 20,0 & $2,07 \mathrm{c}$ \\
\hline 22,5 & $6,68 \mathrm{~b}$ \\
\hline 25,0 & $15,47 \mathrm{a}$ \\
\hline 27,5 & $0,00 \mathrm{c}$ \\
\hline Molhamento & Severidade \\
\hline 0 & $0,00 \mathrm{c}$ \\
\hline 4 & $0,00 \mathrm{c}$ \\
\hline 8 & $0,00 \mathrm{c}$ \\
\hline 12 & $3,71 \mathrm{~b}$ \\
\hline 16 & $2,79 \mathrm{~b}$ \\
\hline 20 & $20,99 \mathrm{a}$ \\
\hline 24 & $6,55 \mathrm{~b}$ \\
\hline $\mathrm{F}_{\text {(Temperatura) }}$ & 29,83 \\
\hline $\mathrm{F}_{\text {(Molhamento) }}$ & 25,37 \\
\hline $\mathrm{F}_{\text {Temperatura x Molhamentos }}$ & 6,24 \\
\hline $\mathrm{CV}(\%)$ & 44,98 \\
\hline
\end{tabular}

*Médias seguidas de mesma letra na coluna não diferem pelo teste Tukey, a $5 \%$ de probabilidade.

Resultados semelhantes no que se refere à temperatura foi observado por Martins, (15) quando estudou o efeito de seis temperaturas (10; $15 ; 20 ; 25 ; 30$ e $\left.35^{\circ} \mathrm{C}\right)$ e seis períodos de molhamentos foliares $(0 ; 4$; $8 ; 12 ; 18$ e $24 \mathrm{~h}$ ) no desenvolvimento da ferrugem alaranjada da canade-açúcar. A autora verificou que a doença desenvolveu-se apenas nas temperaturas de 20 e $25^{\circ} \mathrm{C}$ e que o período de molhamento mínimo para ocorrer à infecção foi de 8 horas. Entretanto no presente trabalho o período de molhamento mínimo de infecção foi de 12 horas. A diferença deste resultado pode estar relacionada as características do hospedeiro já que Martins (15) utilizou a cultivar CL85-1040.

Alves et al. (2), estudando a intensidade da ferrugem asiática (Phakopsora pachyrhizi Sydow) da soja [Glycine max (L.) Merr.] nas cultivares conquista, savana e suprema sob diferentes temperaturas e períodos de molhamento foliar, observaram diferença no período de infecção nas cultivares em estudo e relacionaram essa diferença a característica do hospedeiro, estágio vegetativo e até nutricional, como também devido às combinações entre temperatura e período de molhamento.

Os resultados da interação entre os fatores temperatura e períodos de molhamento foliar expressos na área abaixo da curva de progresso da severidade (AACPDS) da ferrugem alaranjada encontra-se na Tabela 2. Pode-se observar que as melhores temperaturas para o desenvolvimento da doença foram 20,$0 ; 22,5$ e $25,0^{\circ} \mathrm{C}$ sendo a melhor $25,0{ }^{\circ} \mathrm{C}$. Temperaturas abaixo de $20,0^{\circ} \mathrm{C}$ e acima de $25,0^{\circ} \mathrm{C}$ não favoreceram o patógeno, impedindo seu desenvolvimento mesmo quando submetido a altos períodos de molhamento foliar. Existem ainda poucos trabalhos de epidemiologia da ferrugem alaranjada tendo em vista que é uma doença relativamente nova no continente americano sendo necessários mais estudos que confirmem esses resultados.

Já em estudos realizado por Minchio et al. (16) a temperatura ótima de germinação para $P$. kuehnii foi de $21^{\circ} \mathrm{C}$ com período de incubação de $14 \mathrm{~h}$. Em temperaturas em torno de 25 a $30^{\circ} \mathrm{C}$ ocorreu germinação dos uredósporos, porém em porcentagem inferior à temperatura ideal.

Na Tabela 1 pode-se observar ausência de doença no molhamento zero mostrando a necessidade de água livre sobre as folha e de um período de molhamento mínimo de 12 horas para que possa ocorrer infecção da ferrugem alaranjada. Também se verificou que o aumento da intensidade da doença foi até 20 horas de molhamento foliar depois desse período ocorreu um decréscimo da severidade. Nas temperaturas de 22,5 e $25,0^{\circ} \mathrm{C}$ com 20 horas de molhamento foliar observou-se que as plantas desse tratamento apresentaram mais sintomas da doença havendo um decréscimo da severidade quando se teve 24 horas de molhamento (Tabela 2).

Segundo Bedendo \& Amorim (6) os esporos da grande maioria dos fungos patogênicos requerem água livre durante horas na superfície do hospedeiro para germinação e consequentemente penetração. $\mathrm{O}$ aumento da intensidade da doença acompanha o período do molhamento até um determinado limite, a partir do qual a quantidade máxima de doença é atingida e deixa de ser influenciada por períodos adicionais de molhamento. De acordo com Alves et al. (2), a partir de uma determinada concentração de pontos de infecção, as lesões que se formam primeiro, podem dificultar o desenvolvimento de outras que resultam de infecções posteriores.

O período de molhamento foliar e a temperatura têm bastante influência na ocorrência da ferrugem alaranjada como pode ser observado na Tabela 2. Quando se considera todo o ciclo de uma doença todos os fatores ambientais têm importância no processo de infecção, tais como luminosidade, vento, radiação solar e precipitação pluvial, que atuam nos processos de germinação, penetração e disseminação dos esporos (8). Mas dentre os fatores ambientais a temperatura e a umidade relativa são os mais importantes no processo de doença de planta (1).

Com os dados da severidade foi possível determinar a relação entre

Tabela 2. Interação entre os fatores temperatura e horas de molhamento foliar da média da área abaixo da curva de progresso da doença da severidade (AACPDS) da ferrugem alaranjada (Puccinia kuehnii).

\begin{tabular}{|c|c|c|c|c|c|c|c|}
\hline \multicolumn{8}{|c|}{ Horas de molhamento foliar (h) } \\
\hline $\operatorname{Temp}\left({ }^{\circ} \mathrm{C}\right)$ & $\mathbf{0}$ & 4 & 8 & 12 & 16 & 20 & 24 \\
\hline 17,5 & $0,00 \mathrm{aA}$ & $0,00 \mathrm{aA}$ & $0,00 \mathrm{aA}$ & $0,00 \mathrm{bA}$ & $0,00 \mathrm{bA}$ & $2,70 \mathrm{cdA}$ & $2,70 \mathrm{bA}$ \\
\hline 22,5 & $0,00 \mathrm{aB}$ & $0,00 \mathrm{aB}$ & $0,00 \mathrm{aB}$ & $7,85 \mathrm{bB}$ & $16,80 \mathrm{abB}$ & $165,13 \mathrm{bA}$ & $4,80 \mathrm{bB}$ \\
\hline 25 & $0,00 \mathrm{aD}$ & $0,00 \mathrm{aD}$ & $0,00 \mathrm{aD}$ & $82,10 \mathrm{aBC}$ & $37,05 \mathrm{aC}$ & $342,05 \mathrm{aA}$ & $162,31 \mathrm{aB}$ \\
\hline
\end{tabular}

*Médias seguidas de mesma letra minúscula nas colunas e maiúscula nas linhas não diferem entre si, pelo Teste Tukey, a 5\% de probabilidade. 
Model: $\mathrm{v} 3=\left(\mathrm{b} 1^{*}\left((\mathrm{v} 1-\mathrm{b} 2)^{\mathrm{a}} \mathrm{b} 3\right)^{*}\left((\mathrm{~b} 4-\mathrm{v} 1)^{\mathrm{a}} \mathrm{b} 5\right)\right)^{*}\left(\mathrm{~b} 6^{*}\left(1-\mathrm{b} 7^{*} \exp \left(-\mathrm{b} 8^{*} \mathrm{v} 2\right.\right.\right.$ $z=\left((, 595719)^{*}\left((x-(15,2035))^{n}(2,28845)\right)^{*}\left(((27,5)-x)^{\wedge}(, 601 e-5)\right)\right)^{*}\left((2,84424)^{*}(1-(1\right.$ $\left.\left., 03115)^{*} \exp \left(-(, 008219)^{*} \mathrm{y}\right)\right)\right)$

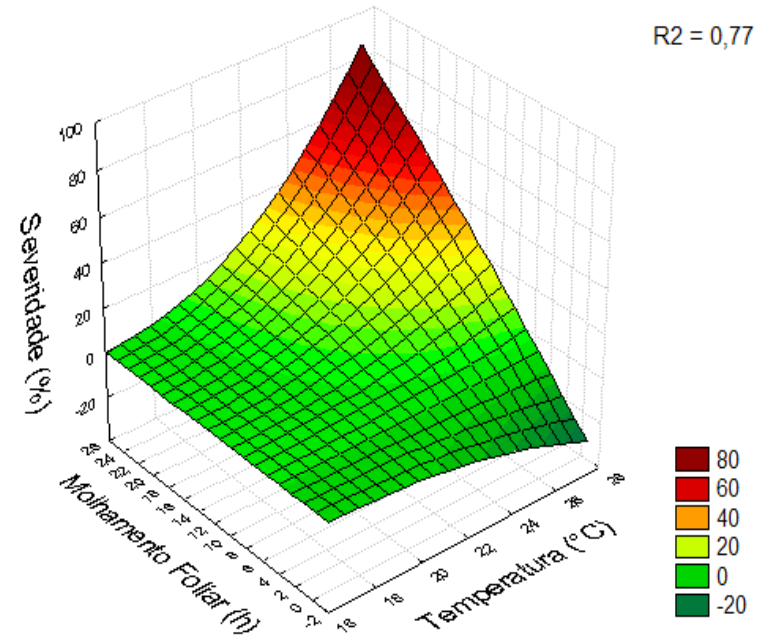

Figura 1. Efeito da temperatura e do período de molhamento foliar no desenvolvimento da ferrugem alaranjada (Puccinia kuehnii) na cultura da cana-de-açúcar.

a temperatura e o período de molhamento foliar através de equação de superfície resposta. Através da equação determinou-se que as condições ideais para o desenvolvimento da doença foram: temperatura de $25,0^{\circ} \mathrm{C}$ e período de molhamento foliar de 20 horas, (Figura 1). Esses dados da epidemiologia da ferrugem alaranjada são bastante importantes para traçar estratégias de controle e futuramente desenvolver um sistema de previsão para a doença.

Com os resultados deste trabalho, foi possível observar que os fatores climáticos estudados, temperatura e molhamento foliar, afetam significativamente a epidemiologia de P. kuehnii, havendo uma interação significativa entre estes fatores.

\section{REFERÊNCIAS}

1. Agrios, G.N. Plant pathology. 5. ed. San Diego: Academic Press, 2005. p. 251- 262.

2. Alves, M. C.; Pozza, E. A.; Ferreira, J. B.; Araújo, D. V.; Costa, J. C. B.; Deuner, C. C.; Muniz, M. F. S.; Zambenedetti, E. B.; Machado, J. C. Intensidade da ferrugem asiática (Phakopsora pachyrhizi H. Sydow \& $\mathrm{P}$. Sydow) da soja [Glycine max (L.) Merr.] nas cultivares Conquista, savana e suprema sob diferentes temperaturas e períodos de molhamento foliar. Summa Phytopathologica, Botucatu, v.33, n.3, p.239-244, 2007.

3. Amorim, L.; Bergamin Filho, A.; Sanguino, A.; Ardoso, C.O.N.; Moraes, V.A.; Fernandes, C.R. Metodologia de avaliação de ferrugem da cana- de-açúcar (Puccinia melanocephala). Boletim Técnico Copersucar: São Paulo, n.39, p.13-16. 1987.

4. Araújo, K.L.; Gilio, T.A.S.; Sanches, P.R.B.; Neubauer, R.A.; Fagundes, C.; Bassan, B.E.; Rodero, D.C.P.; Giglioti, E.A.; Canteri, M.G. Monitoramento da favorabilidade genotípica para ocorrência da ferrugem alaranjada da cana-de-açúcar no Brasil. Tropical Plant Pathology, Brasília: Associação Brasileira de Fitopatologia, v. 36, supl. p. 839, 2011.

5. Barbasso,D.; Jordão, H.;Maccheroni,W.; Boldini,J.;Sanguino,A. First report of Puccinia kuehnii, causal agent of orange rust of sugarcane, in Brasil. Plant Disease, Saint Paul,v.94, p.1170-1170, 2010. Doi: 10.1094/PDIS - 94 -9 -1170C.

6. Bedendo, I.P.; Amorim, L. Ambiente e doença. In: Amorim, L.; Rezende, J.A.M.; Bergamin Filho, A. (Org. ). Manual de Fitopatologia: Princípios e conceitos. 4.ed, São Paulo: Ceres, 2011. v.1, 4 ed, p. 133-147.

7. CONAB - Companhia Nacional de Abastecimento (2017), Observatório Agrícola: Acompanhamento da safra brasileira (Cana-de-açúcar) Terceiro levantamento (Safra 2016/2017), v.3, n.3, 2016. Disponível em: http:// www.conab.gov.br/OlalaCMS/uploads/arquivos/16_12_27_16_30_01_boletim_cana_portugues_-3o_lev_-_16-17.pdf. Acesso em: 30/01/2017.

8. Ferrari, J.T; Harakava, R; Domingues, R.J; Terçariol, I.M.L. Ferrugem alaranjada da cana-de-açúcar. Documento Técnico do Instituto Biológico (APTA), São Paulo n.5, p.1-8, 2010. Disponível em: www.biologico.sp.gov. br. Acesso em: 23/01/2013.

9. Gillespie, T.J. Pest and disease relationships. In: Griffiths, J.F. Handbook of agricultural meteorology. New York: Oxford University Press, 1994. Chap 19, p. $203-209$

10. Hau, B.; Kranz, J. Mathematics and statistics for analyses in epidemiology. In: Kranz, J. (Ed). Epidemics of plant disease: mathematics analyses and modeling. Berlin. Springer Verlag, p. 12-52, 1990.

11. Hoppmann, D.; Wittich,K.P. Epidemiology related modeling of the leaf wetness duration as an alternative to measurements, taking Plasmopora viticola as an example. Zeitschrift für Pflanzenkrankheiten un Pfflanzenschutz, Germany, v. 104, p. 533 - 544, 1997.

12. Magarey, R.C.; Willcox, T.; Croft, B.; Cordingley, A. Orange rust, a major pathogen affecting crops of Q124 in Queensland in 2000. Proceedings of Australian Society of Sugar Cane Technology, Queensland, v. 23, p. 274-280, 2001.

13. Magarey, R.C. Orange rust. In: Rott, P.; Bailey, R.A.; Comstock, J.C.; Croft, B.J.; Girard, J.C.; Saumtally, A.S. A guide to sugarcane diseases. Montpellier: La Librairie du Cirad, 2000. p. 121-125.

14. Magarey, R.C.; Neilsen, W.A.; Magnanini, A.J. Environmental requirements for spore germination in the three sugarcane leaf pathogens. In: Conference of the Australasian Society of Sugar Cane Technologists held at Brisbane, Queensland, 2004. p. 1-7.

15. Martins, T.D. Aspecto epidemiológico da ferrugem alaranjada da cana-de-açúcar. 2010, 65f. Tese (Doutorado em Fitopatologia) - Escola Superior de Agricultura " Luiz de Queiroz”, Universidade de São Paulo, Piracicaba, 2010.

16. Minchio, C. A.; Canteri, M.G.; Rocha, J.A. Germinação de uredósporos de Puccinia kuehnii submetidos a diferentes temperaturas e tempos de incubação. Summa Phytopathologica, Botucatu, v.37, n.4, p.211-214, 2011.

17. Shaner, G.; Finney, R.E. The effect of nitrogen fertilization on the expression of slow - mildewing resistance in Knox wheat. Phytopathology, St. Paul, v.67, n.8, p.1051-1056, 1977. 